\title{
Building intercultural teachers: Designing information literacy instruction opportunities for increasingly international populations.
}

\section{Introduction}

Even before the current boom in international student enrolment within higher education (American Council on Education, 2012), academic librarians have a long history of supporting newcomer adjustment to different scholarly contexts. This support has been made manifest through a variety of initiatives, of which information literacy teaching forms one of the most common (see Peters, 2010). The desire to help newcomers settle in and succeed in their new setting is, as Powell (2014) points out with reference to retention narratives, an idea against which it is hard to argue. However, research illustrates that an uncritical acceptance of the ways in which librarians attempt to assist international populations may serve to complicate rather than to facilitate engagement within culturally unfamiliar information environments (Conteh-Morgan, 2003; Hicks, 2016, Hicks \& Lloyd, 2016). This is particularly the case for information literacy initiatives, where universal approaches to instruction position incoming international students as toiling under the burden of their difference and their engagement within a new setting as a struggle that is 'managed' through librarian intervention (Hicks \& Lloyd, 2016). The tendency to dismiss the sociocultural influences that impact how a person is able to engage with the learning opportunities (Billett, 2001) of a new setting means that international student information literacy instruction is further reproached for silencing diverse perspectives and limiting the employment of centring and inclusive pedagogies (Hicks, 2016).

This paper will address these critiques by presenting a series of recommendations for the design of information literacy teaching initiatives for international students, who are defined as learners who are engaged in higher education in a country different to their own. Recommendations are drawn from doctoral research that explored the information literacy practices of 26 English-speaking students who were learning a language overseas. As the methods and the findings of this study have been explored in detail elsewhere (Hicks, 2018b; Hicks \& Lloyd, 2018), this paper will focus on presenting and exploring the practical recommendations that emerged from this study. The paper's focus on the implications of the research study rather than on the study itself is designed to acknowledge and centre the work of teaching librarians and educators, many of whom have been expected to deal with the consequences of an increasingly international campus without a corresponding increase in support levels (Volet \& Jones, 2012). The emphasis on practical recommendations is also designed to bridge the increasing gap between conceptual and applied understandings of information literacy (Lloyd, 2017) by giving equal weighting to the everyday inferences that can be made from empirical information literacy research as much as to its contributions to the development of theoretical understandings. As a consequence, this paper will be of interest to librarians and study abroad professionals who are engaged in the provision of information literacy instruction as well as educational programming on an increasingly international campus.

The recommendations that constitute the focus of this study emerged from a qualitative study that took a sociocultural perspective to information literacy, which is defined in this paper as a "way of knowing the many environments that constitute an individual's being in the world," (Lloyd, 2007, p.182). A sociocultural approach, which positions information literacy as situated and shaped through the ways in which information is valued within a specific setting, moved the focus of the study from the measurement of skills to an exploration of the ways in which language-students built understanding within a new information environment. The emphasis on 
interaction also acknowledged the complexity of student engagement overseas as they mediated the tensions and conflicts that emerged through their participation within the practices of a new community. This study additionally chose to focus on the activities of English-speakers who were studying overseas rather than, as is more typical, students from non-majority Englishspeaking environments. The emphasis on English-speakers was designed to provide a comparative perspective to existing studies of international students as well as to extend understandings of information literacy within intercultural settings (cf. Bruce, Somerville, Stoodley \& Partridge, 2013, p.225).

\section{Literature Review}

Literature that explores academic information literacy for international populations has been increasing steadily since the 1990s (Click, Walker Wiley \& Houlihan, 2017). This literature mirrors the growth of international student enrolment within higher education in the United States as well as in other English-speaking countries (American Council on Education, 2012) and has helped to draw attention to the impact that cultural differences as well as the need to work in a second or third language has on student engagement in the library (e.g. Bordonaro, 2006; Han, 2012; Hughes, 2009). The emphasis on the challenges that international students face within a new information environment has further led to a growth in research that explore the provision of culturally appropriate instructional opportunities. These studies, which highlight the adjustments that librarians can make to accommodate diversity in their information literacy teaching, including improving listening skills (e.g. Amsberry, 2009) as well as collaborating with ESL teaching faculty (e.g. Conteh-Morgan, 2002), illustrate increasing interest in the design of appropriate teaching interventions. The growing legitimisation and popularisation of research in the area has additionally encouraged a more nuanced understanding of international student populations; while literature initially took a very broad approach, it has since started to focus on specific populations of international students, including English as a Foreign (EFL)/Second Language (ESOL) students (e.g. Johnston, 2014), graduate students (e.g. Reyes, Hicks \& Maxson, 2018) and comparative studies of domestic and international students (e.g. Zhao \& Mawhinney, 2015). The changing focus of research addresses criticisms about the perceived homogeneity of the international student label (Conteh-Morgan, 2003; Hicks, 2016), while further demonstrating how the internationalisation of campus has led to a greater need to develop understanding about questions of intercultural information literacy education.

At the same time, the overwhelming tendency to approach international student information literacy through the lens of culturally specific national standards and frameworks (e.g. ACRL, 2000) means that existing literature has also been critiqued for perpetuating biased models of education rather than leading to the development of culturally relevant educational interventions (Hicks \& Lloyd, 2016). An emphasis on the measurement of information skills, for example, is seen to position information literacy instruction as a unilateral process of assimilation to the Western values that are embedded within these 'neutral' models of practice (Volet \& Jones, 2012, p.243). Librarians have also been critiqued for creating and perpetuating essentialised stereotypes when international student linguistic or cultural difference is blamed for their reported deficiencies (Conteh-Morgan, 2003). Research is similarly criticised for centring individual processes rather than social practices (Hicks \& Lloyd, 2016). While an emphasis on international student understanding of their own activities emphasises complexity rather than deficiency, a failure to account for the broader sociocultural dynamics that structure engagement within a new information environment paints a limited picture of the ways in which they engage 
with information. Explored at length in a separate paper (Hicks, 2016), these actions are particularly problematic given the goals of the global campus; although diversity may be celebrated in educational mission statements, this literature shows that it swiftly becomes seen as a problem within the classroom (Lillis \& Scott, 2007, p.8).

Literature has also been limited by the research methodologies and approaches that have previously been used to understand international student information literacy. Personal librarian experiences (e.g. Badke, 2011) and surveys have formed the most common ways to explore international student information literacy with Click, Walker Wiley and Houlihan (2017) noting that over half of the papers that they identified in their systematic review of international student information literacy employing surveys as their only research method. While these approaches may help to establish correlation between 'successful' adaptation and individual or institutional demographics, they make it particularly hard to move beyond superficial or librarian-led understandings of international student information literacy. The emphasis on one-off assessments of proficiency also makes it harder to see international student adjustment to new settings in terms of longer-term change processes (Volet \& Jones, 2012, p.252). Research is further restricted by the failure to explore international student information literacy in the context of all student adjustment to culturally unfamiliar settings with 22 out of the 23 studies that were examined in Click, Walker Wiley and Houlihan's (2017) systematic review of international student information literacy emerging from majority-Anglophone countries. In contrast, Hyldegård and Hertzum's study of international students in Denmark (2016), which forms one of the few to focus on a non-majority English setting, demonstrates how an engagement with outgoing as well as incoming students can unpack assumptions about the ways in which newcomers mediate new information environments.

In sum, although the global dimensions of higher education continue to grow in importance within libraries (Kutner \& Armstrong, 2012), literature that explores international student information literacy has been limited by its focus on individual process and decontexualised settings rather than the complex ways in which newcomers engage with information in a culturally unfamiliar setting. Studies that emphasise individual information skills pigeonhole incoming students and reinforce beliefs in the superiority of Western education (Montgomery \& McDowell, 2009, p.456). At the same time, studies that focus on the development of individual 'habits of mind' neglect to account for the active dynamics of a new context or the ways in which international students both position themselves and are positioned by others whilst they are overseas. These oversights illustrate how a more solid research base is needed for the design of international student information literacy education.

\section{Study overview}

The recommendations that are the focus of this paper emerged from a study that explored the information literacy practices of 26 English-speaking language-learners who were temporarily engaged in work or study abroad as part of their undergraduate degree. This period of time, which is known as the "year abroad" in the United Kingdom and "Study Abroad" or "Exchange" in North America and Australia, plays an important role within undergraduate education as language-learners are forced to adjust from learning about to practising a language within their target language community. Given the intensity of this period as well as the importance of global learning on campus as well as in broader social, workplace and community contexts, this study explored students' adjustment to a new setting through the following research questions: 
- How do language-students enact information literacy practices during time overseas?

- How do language-students make sense of, transition into and come to know their new information landscapes?

As the study's findings and methods have been explored at length in other venues (Hicks, 2018b, Hicks \& Lloyd, 2018) and the focus of this paper is the recommendations that emerged from this research, this section provides a brief contextualising overview of the original research approach.

\subsection{Theoretical Framework}

This research was situated within an interpretivist framework and informed by symbolic interactionism and social constructionism. Symbolic interactionism emphasises that reality is created through the assignation and interpretation of shared meaning (Blumer, 1969). This study's employment of symbolic interactionism positioned information literacy as explored through the ways in which international students actively engaged in and reflected upon the ways in which they interacted in the world rather than as forming a pre-established model or framework, as the study's open-ended research questions demonstrate. Social constructionism positions human perception, knowledge and social reality as built and sustained through social processes (Burr, 1995, p.4). The use of a constructionist lens positioned knowledge as a communal rather than an individual possession and highlighted the centrality of dialogue within the articulation and shaping of international student information literacy. The study also employed transitions theory (Meleis, Sawyer, Messias, Im \& Schumacher, 2000) and practice theory (Schatzki, 2002) as the two major theories through which the findings of this study were analysed. Transitions theory (Meleis et al., 2000) emphasises the ways in which humans mediate complex processes of change and provided a structure to explore students' transformative engagement within a new information environment. Practice theory (Schatzki, 2002) establishes social practices rather than people as central to social life and focused attention on the changing, materially-mediated and embodied shape of student information activities overseas. This framework set the stage for the production of rich and student-centred understandings of information literacy.

\subsection{Method}

\subsubsection{Data collection and analysis}

This study employed a constructivist grounded theory method of inquiry (Charmaz 2014). The constructivist grounded theoretical approach facilitated the construction of theoretical understanding about information literacy that was grounded in data while further foregrounding what was important to participants rather than just to the researcher. Data were collected through the employment of semi-structured interview methods and photo-elicitation visual research methods. Interview methods were selected to allow each participant to reflect on and present their explanatory narrative of their time overseas. Interview questions were modified and developed through ongoing interaction with participants and focused on exploring typical everyday rather than academic pursuits, such as choosing a supermarket, opening a bank account and establishing leisure activities. Photo-elicitation methods, which asked participants to take photographs of anything that had helped them to learn about or settle into their new context, were selected to elicit the contextual or taken for granted meaning that is hard to verbalise (Hicks $\&$ Lloyd, 2018). Interview data were subsequently transcribed in full, although I removed distracting features of spoken talk and added in punctuation to produce the readable transcripts 
that are suitable for grounded theory. Photos were discussed at the second interview and these discussions were incorporated into the interview transcripts rather than being analysed separately. Data were subsequently analysed using grounded theory and situational analysis methods.

\subsubsection{Sample}

The study's sample comprised 26 language-learners, who were interviewed twice using a video conference tool for a total of 52 interviews, and who took 160 photos for an average of seven per participant. Participants were selected through a maximum variation purposive sampling strategy and comprised English-speakers from Australia (3), Canada (3), the United States (8) and the United Kingdom (12). Participants were studying eight European and Asian languages (French, German, Icelandic, Italian, Japanese, Mandarin, Russian, Spanish) within a total of 14 countries, which covered seven European locations (Austria, Belgium, France, Germany, Iceland, Italy, Spain), four in the Americas (Bolivia, Canada (Quebec), Chile, Guadeloupe), three in Asia (China, Hong Kong, Japan), one in Eurasia (Russia) and one in Africa (Melilla). Most participants spent their time abroad studying (17), although a significant proportion of participants (nine) were employed during this time, including taking a private internship or position (four), participating in the British Council teaching assistantship scheme (four) and volunteering (one). Students were recruited through a website that was sent to study abroad directors and librarians. No country or language of study was ruled out, although students who were not studying a language or whose placements lasted for fewer than 30 days were excluded to maintain the study's focus on language-learning. Due to the time and effort involved in gathering visual data, participants were offered a USD\$40 (or its local equivalent) gift card in exchange for participation in this research.

\subsubsection{Limitations}

The study was subject to several limitations, including a reliance on video-mediated interview communication with participants. The request to photograph the complex concept of information meant that the use of photo-elicitation methods may also have constituted a limitation. To offset these issues, I prioritised building rapport with each participant, while additionally checking their comprehension of the photography task. I also used the second interview to discuss each participant's photographs as well as offering students an opportunity to critique my emerging analysis. Another important limitation related to the narrowness of the sample. While no host country or language was excluded from the research, most potential participants were studying French, German and Spanish in Europe. As the most popular languages that are studied within North American higher education (MLA, 2013), these figures were expected but it meant that it was much harder to find potential participants from locations with less well-developed language study infrastructures such as Africa. In terms of occupation, the popularity of study abroad or exchange activities in North America and Australia meant that it was almost impossible to find participants from these countries who were planning to work or volunteer abroad. This meant that working students were uniquely represented by participants from the United Kingdom.

\subsection{Findings}

Findings from this study, which have been explored elsewhere in more detail (Hicks, 2018b), identified that language-students engaged in several key information activities as they attempted to negotiate their adjustment to and participation within a culturally unfamiliar setting. These 
activities configured two categories, Calibrating and Repositioning. Calibrating refers to the adjustments that language-learners make through comparison to more experienced others, including locals, native speakers and recently-returned students. Constituted through the sifting of information to identify the core characteristics of a setting; the observing of others and of oneself to become aware of local practices; the checking of information to validate their activities within a setting; and the noting of information to regulate their performance over time, calibrating provided language-learners with the means to orient themselves to local values and expectations. Repositioning refers to how language-students situate themselves in and in relation to a new information environment. Comprising the triaging of information questions and interactions to channel their engagement overseas; the mediating of information to friends and family back home to validate their expertise within a setting; and, the archiving of information to uphold their credibility as a language-student over time, repositioning provided a way for language-learners to manage their participation within a new social context, including in response to the linguistic, cultural and physical barriers that limited their opportunities to engage within a new information environment.

These information activities were subsequently drawn together to configure the overarching category and the emerging grounded theory of mitigating risk. The theory of mitigating risk states that the academic, financial and physical stresses that are produced through language-students' engagement within a new information environment catalyse the enactment of the information literacy practices that subsequently mediate students' transition from acting like a language-learner to becoming a language-learner within the structures of their new setting. Illustrating how language-learners' time overseas is structured by risks that are intensified by the uncertainty and time pressures of this period, the theory of mitigating risk demonstrates how information literacy, as represented by calibrating and repositioning, forms the means through which students can mediate the potential impact of these pressures on their time overseas. In further highlighting how an engagement in calibrating and repositioning marks a shift in identity and agency, as students start to situate and redefine themselves in relation to collective ways of knowing, the theory of mitigating risk also draws attention to student transition, which is seen as enabled and constrained through the enactment of information literacy practices. Providing a rich empirical picture of how students rebuild understanding during a time of change and upheaval, findings from this study also illustrate how engagement within a culturally unfamiliar setting forms both a time of challenge and opportunity.

\section{Recommendations}

The paper will now present the implications and recommendations for the design of international student information literacy instruction initiatives that emerge from this study.

\subsection{Reframe newcomer engagement within a new information environment in terms of transition The first recommendation to emerge from this study is to reframe international student information literacy instruction in terms of transition rather than the acquisition of remedial skills. The concept of transition has not been widely explored within information literacy research, despite the centrality of change and development to the field. When transition has been mentioned, it has typically been used to refer to events that require a learner's engagement in new information activities, such as the shift from secondary to tertiary education (e.g. Burhanna, 2013) or as a transfer student between colleges (e.g. Ivins, Copenhaver \& Koclanes, 2017). However, the recognition that a move from the classroom to an immersive learning environment}


forms a significant disruption in life circumstances suggests that overseas engagement forms a similarly complex transitional event (also see Hughes, Cooper, Flierl, Somerville \& Chaudhary, 2018). From a teaching perspective, an emphasis on transition is important because it moves the focus of international student information literacy from 'fixing' people to a recognition that students are rebuilding meaning within culturally unfamiliar information environments. The acknowledgement that these transitional processes are both drawn out and emotionally-charged also suggests the need to design learning opportunities that scaffold the intensity of these changes rather than disregarding them. These ideas are further substantiated through the recognition that a learner's international student label is intricately interwoven with other identity markers, such as being a first-generation college student (Hicks, 2016, p.48), and that students may be engaging in multiple transitions at once.

At the same time, the concept of transition cannot merely be conceived as a convenient way to frame alterations within students' educational circumstances. Instead, the recognition that language-students mediate change through their engagement in a variety of sophisticated information activities illustrates how transition centres on the shifts that they make to integrate disruption into their life (Schumacher \& Meleis, 1994, p.121) rather than physical and unidirectional movement between settings. The acknowledgement that language-student transition is mediated through and in relation to their engagement within a new information environment suggests the need to recognise the situated shape of international student information activities; the possession of generic information literacy skills, like demographics and other individual traits, cannot be seen to form an independent variable that will determine a 'successful' transition. Similarly, the emphasis on the rebuilding of meaning implies that there is a need to appreciate the multiple and often idiosyncratic ways in which international students negotiate the intensity of this time rather than making assumptions about what constitutes effective information activity (cf. Hughes, 2009). In this light, international student information literacy education opportunities should be designed to foster rather than to marginalise or impose the means through which newcomers make connections to new ways of knowing.

The recognition that language-learner information activities facilitate the shift from acting like to becoming a language-learner overseas further acknowledges how transition centres on the simultaneous forming and reforming of subjectivity. As Kralik, Visentin and van Loon point out (2006, p.324), mastery of a situation cannot be separated from a shift in self-identity. Transition subsequently becomes positioned as a time of reconstruction and transformation as language-student engagement in information activities helps them to build what Wenger (1998, p.56) refers to as an "identity of participation" through and in relation to a community's shared ways of knowing. Language-students' changing roles and responsibilities imply the importance of information literacy education that acknowledges how international students are participating in complex processes of being, becoming and unbecoming (Fenwick, 2013, p.362) rather than displaying cultural deficiencies. The cultural dynamics of this time, which may include acclimation to living as an ethnic or linguistic minority in a majority culture, further suggest the need for information literacy teaching that recognises the multi-faceted shape of international student transition as well as the impact of these changes on the ways in which students engage with information.

In sum, the acknowledgement that a move overseas forms a period of complex change means that the concept of transition provides a useful way to reframe international student information literacy instruction. At the same time, the recognition that the rebuilding of knowing is elaborate implies that librarians and educators should take a nuanced approach to the creation 
of appropriate support mechanisms. While transition produces difficulties and challenges, it can also form a time of generative possibilities as students engage with new ideas and explore different ways of knowing. These ideas suggest that international student information literacy instruction should refrain from attempting to 'ease' difficulties, which runs the risk of creating normative depictions of 'successful' transitions and reinforcing the assumption that international students are unable to navigate transition without formal support (cf. Ecclestone, 2009, p.23).

\subsection{Recognise that information literacy centres on negotiation rather than on assimilation}

The second recommendation of this study is to recognise that information literacy centres on students' negotiation of an unfamiliar information environment rather than on their assimilation into a new setting. Explorations of the ways in which international students engage within new information environments have typically minimised student agency; newcomers are expected to absorb the norms of their new setting unproblematically and information literacy instruction is perceived to form a vehicle that will facilitate these acculturation and socialisation processes. Even when studies take a more learning-centred approach to understanding international student information literacy (e.g. Bordonaro, 2006; Hughes, 2009), literature still tends to neglect to account for individual positioning and the active dynamics of a situation, including "the multidimensional tension and conflict students experience in a transnational situation" (Kim, 2011, p.457). In contrast, the recognition that language-students engage in repositioning to maintain their opportunities to engage with information within a new setting implies that international newcomers are often forced to negotiate their ongoing access to new information environments rather than unproblematically being assimilated to new ways of knowing. From a teaching perspective, the emphasis on negotiation suggests the importance of designing information literacy instruction for complex dynamics rather than for standardised and linear developmental pathways.

More specifically, the acknowledgement that language-students engage in repositioning information activities in reaction to local judgements about their physical characteristics such as race or ethnicity as well as their linguistic competence (cf. Billett, 2001, p.210) suggests the need to recognise that international student information literacy is mediated through the dynamics of social interaction rather than uniquely through individual motivations and goals for this time overseas. The study's use of transitions theory, which highlights that social and community conditions such as the presence of discrimination and the existence of support networks affect how people are able to respond to change (Meleis et al., 2000), further implies that a newcomer's ability to mediate transition is impacted by material circumstances as well as by the social structures of their new setting. For teaching purposes, the important role that the conditions of a setting play in structuring language-student engagement within a new information environment suggests the importance of instructional models that move beyond neutral contexts and artificially tidy simulations of practice. Instead, the recognition that language-student information literacy practices are shaped through and in relation to the power structures of their new settings suggests that international student information literacy instruction should focus on scaffolding a critical engagement with the "messy complexities" (Gourlay, 2017, p.33) of a new information environment rather than ideological goals for future achievement.

At the same time, the recognition that language students exercise their agency in the face of the structural barriers that limit their access to shared and collective understandings suggests the need to acknowledge that international students play an active rather than a passive role in mediating their engagement within a new information environment. Newcomers have typically 
been positioned as uninvolved with their adjustment to a new context, as evidenced by the tendency within information literacy literature to treat international students as recipients of assistance rather than as knowledgeable individuals who are experts in their own activities (Reyes et al., 2018). The elision of student agency, which may reflect the influence of psychological models of acculturation that position international movement as centred on an unquestioning induction into dominant social norms (Volet \& Jones, 2012, p.246), is further reinforced by the depiction of adaptation to a new setting as needing to be managed by support staff (Ecclestone, 2009, p.23). However, the recognition that language-students "reflect upon, feel about, and act on their experiences" (Volet \& Jones, 2012, p.247) as they shape and develop the information activities that help them to navigate complex information environments suggests that international student information literacy instruction should support the active interrogation of community values rather than merely focusing on their mechanical reproduction. Importantly, a focus on agency implies that there is also a need to acknowledge students' capacity to resist or redirect learning towards their own goals; as Gibson (2018) points out, disengagement may be a purposeful and protective strategy that international students employ in the face of marginalisation.

\subsection{Design for sociality, connections and interaction}

The third recommendation of this study is to design information literacy instruction for social interaction. Information literacy has typically been seen as a solitary academic practice where people work, learn and perform in isolation (Harris, 2008, p.250). While the recent ACRL Framework for Information Literacy (2015) has acknowledged the importance of the collective through the inclusion of "communities of learning" within its definition of information literacy, the emphasis of these documents still remains centred upon individual endeavour. However, the important role that social relationships and the bodies of experienced others play in structuring language-student engagement in calibrating and repositioning suggests the importance of designing information literacy teaching interventions that centre on and facilitate social connections. As Harris (2008, p.251) points out, an emphasis on community "completely change[s] the information literacy event in and of itself" rather than merely highlighting the need for more groupwork. More importantly, the important role that information activities such as observing play within the development of knowing, which form what Billett $(2001$, p.4) labels as an "unintended" social learning strategy, suggests the need to create both formal and informal learning opportunities within the design of teaching interventions. Language-student engagement in mediating, where they share information with friends and family back home as a way to build the social and emotional support they need to engage within a culturally unfamiliar information environment, further implies the importance of centring the affective dimensions of engagement abroad within international student information literacy education.

At the same time, the recognition that language-students often find it difficult to build the social relationships that will facilitate their access to the information tools, activities and sources that are valued within a setting suggests a need to purposefully design information literacy instruction that will facilitate interaction and connection. The brevity of language-students' stays overseas indicates how they often do not have the time or the opportunity to build the social contacts that will engage them within a new information environment. Student reliance on friends and family back home further demonstrates how their ability to build the local social support networks that will help them to maintain their engagement within new information environments is restricted. These difficulties consequently suggest the need to think more 
broadly about the shape that international student information literacy instruction could take. Most recently a handful of librarians have spearheaded projects that were designed to facilitate learners' intercultural interactions, including speed-friending (Bridges, 2014), candlelit dinners (Lauerson, 2015) and conversation cafes (Johnston, 2016, 2017). The recognition that events such as these help international students to rebuild support networks while further engaging learners with the tacit and nuanced conventions of their setting demonstrates the importance of continuing to explore the design of information literacy educational opportunities within everyday spaces (Lloyd \& Wilkinson, 2017) as well as in the classroom.

\section{Conclusion}

The need to be able to engage with linguistic and cultural difference on educational, social and industry levels illustrates the importance of designing information literacy instruction for increasingly global societies. However, as previous critiques of international student information literacy initiatives have hinted (Conteh-Morgan, 2003; Hicks, 2016; Hicks \& Lloyd, 2016), the internationalisation of campus cannot merely be seen as an excuse to precipitate the expansion of traditional models of information literacy instruction. Instead, librarians and educators must also appraise and deconstruct dominant pedagogical values and frameworks to engage with the complex challenges of creating inclusive and centring educational spaces for international students. This paper aims to address these issues by presenting a series of recommendations for the design of instructional opportunities within increasingly international societies. Drawing from research that explored the information literacy practices of language-learners overseas, these recommendations have highlighted the importance of incorporating ideas of transition, negotiation and connection into international student information literacy instruction. At the same time, it is important to recognise that these recommendations reflect the local context in which the research took place as well as the need for further research in the area.

More specifically, the recommendations that emerged from this study illustrate the need to move beyond what Volet and Jones (2012) have labelled as unilateral models of education, where the responsibility for adaptation to new cultural contexts is uniquely seen to rest with the international student. While the intent of these approaches is laudable, an emphasis on 'accommodating' cultural diversity merely heightens international students' otherisation by positioning these newcomers as the only ones to cause problems in the classroom (Volet \& Jones, 2012, p. 257). Instead, the recognition that an international student's sojourn overseas forms a period in which they are rebuilding understanding within culturally unfamiliar information environments demonstrates the need to develop models of information literacy education that centre on the idea of transformation rather than adaptation. A transformative educational approach, which reframes teaching and learning activities in terms of what learners are becoming rather than what is learnt, calls for information literacy education that engages with the complexity of identity-development, as well as recognising the varying shape of students' roles and responsibilities within a new setting. An emphasis on transformative change also illustrates how the internationalisation of campus forms an opportunity that is shared between domestic students and librarians as well as international newcomers.

These recommendations also raise a number of questions about the broader shape of information literacy teaching and learning practices. The ACRL Framework (2015), which forms a guiding information literacy document within the United States, provides a set of core conceptual understandings about the shape that information literacy takes within higher education. However, although language-students constitute part of the group of learners for 
whom the Framework was designed, recommendations from this study illustrate that the ways in which they engage with information looks very different from how information literacy is presented within institutional documents. These disparities are troublesome given the important role that global learning plays within higher education. They also point to broader problems within the design of the Framework; while its employment of threshold concept theory was designed to establish the essential ideas of information literacy within higher education, recommendations from this study illustrate that these 'core' understandings may not hold true within an intercultural context. As various commentators have pointed out, threshold concepts may look very different for different people and within different contexts (Morgan, 2015; Wilkinson, 2014). In effect, findings from this study illustrate the inherent complications when educational frameworks and standards are designed in isolation from learner-centred empirical research. The recognition that a sojourn overseas forms both a challenge and an opportunity further demonstrates the continued need to explore international student information literacy from the perspective of newcomers, or the people who are directly engaged with the complex and messy processes of learning how to interact with information within a new setting (Hicks, 2018a; Reyes et al. 2018).

\section{References}

American Council on Education (ACE). (2012). Mapping internationalization on U.S. campuses. Available at: http://www.acenet.edu/news-room/Pages/Mapping-Full-Report.aspx

Amsberry, D. (2009). Using effective listening skills with international patrons. Reference Services Review, 37(1), 10-19.

Association of College and Research Libraries (ACRL) (2000). Information literacy competency standards for higher education. Retrieved from www.ala.org/ala/acrl/acrlstandards/standards.pdf

Association of College and Research Libraries (ACRL). (2015). Framework for information literacy for higher education. Available at http://www.ala.org/acrl/standards/ilframework

Badke, W. (2011). Multicultural infolit. Online 35(1), 51-53.

Billett, S. (2001). Learning through work: Workplace affordances and individual engagement. Journal of Workplace Learning, 13(5), 209-214.

Blumer, H. (1969). Symbolic interactionism: Perspective and method. Englewood Cliffs, NJ: Prentice-Hall.

Bordonaro, K. (2006). Language learning in the library: An exploratory study of ESL students. Journal of Academic Librarianship, 32(5), 518-526.

Bridges, L., (2014). Speed friending in the library. Info-fetishist. Available at: https://infofetishist.org/2014/05/12/guest-post-speed-friending-in-the-library/

Bruce, C., Somerville, M., Stoodley, I. \& Partridge, H. (2013). Diversifying information literacy research: An informed learning perspective. In: M. Hepworth \& G. Walton (Eds), Developing people's information capabilities: Fostering information literacy in educational, workplace and community contexts (pp.223-240). UK: Emerald.

Burhanna, K.J. (2013). Informed transitions: Libraries supporting the high school to college transition. Santa Barbara, CA: Libraries Unlimited.

Burr, V. (1995). An introduction to social constructionism. London: Routledge.

Charmaz, K. (2014). Constructing grounded theory. London: SAGE Publications.

Conteh-Morgan, M. (2001). Empowering ESL students: A new model for information literacy instruction. Research Strategies, 18(1), 29-38. 
Conteh-Morgan, M. (2002). Connecting the dots: Limited English proficiency, second language learning theories, and information literacy instruction. The Journal of Academic Librarianship, 28(4), 191-196.

Conteh-Morgan, M. (2003). Journey with new maps: adjusting mental models and rethinking instruction to language minority students. In: H. Thompson (Ed), Learning to make a difference: Proceedings of the eleventh national conference of the Association of College and Research Libraries (pp.257-66). Chicago: ACRL.

Click, A., Wiley, C., \& Houlihan, M. (2017). The internationalization of the academic library: A systematic review of 25 years of literature on international students. College \& Research Libraries, 78(3), 328-358.

Ecclestone, K. (2009). Lost and found in transition: Educational implications of concerns about 'identity', 'agency' and 'structure'. In: J. Field, J. Gallacher \& R. Ingram (Eds), Researching transitions in lifelong learning (pp.9-27). London: Routledge.

Fenwick, T. (2013). Understanding transitions in professional practice and learning: Towards new questions for research. Journal of Workplace Learning, 25(6), 352-367.

Gibson, A. (2018). “Can I ask that?” Respectability and geographies of fear among Black and Latina tween (and teen) information Seekers. Paper presented at Libraries in the Digital Age conference.

Gourlay, L. (2017). Student engagement, 'learnification' and the sociomaterial: Critical perspectives on higher education policy. Higher Education Policy, 30(1), 23-34.

Han, J. (2012). Information literacy challenges for Chinese PhD students in Australia: A biographical study. Journal of Information Literacy, 6(1), 3-17.

Harris, B.R. (2008). Communities as necessity in information literacy development: Challenging the standards. The Journal of Academic Librarianship 34(3), 248-255.

Hicks, A. (2016). Reframing librarian approaches to international student information literacy through the lens of New Literacy Studies. In: S. McNicol (Ed), Critical literacy for information professionals (pp.43-56). London: Facet.

Hicks, A. (2018a). Making the case for a sociocultural perspective on information literacy. In: K. Nicholson \& M. Seale (Eds.), The politics of theory and the practice of critical librarianship (pp.69-85). Duluth, MN: Library Juice Press.

Hicks, A. (2018b). The theory of mitigating risk: Information literacy and language learning in transition. Published doctoral thesis, Swedish School of Library and Information Science, University of Borås, Sweden.

Hicks, A. \& Lloyd, A. (2016). It takes a community to build a framework: Information literacy within intercultural settings. Journal of Information Science, 42(3): 334-343.

Hicks, A. \& Lloyd, A. (2018). Seeing information: Visual methods as entry points to information practices. Journal of Librarianship and Information Science.

Hughes, H. (2009). International students using online information resources to learn. $\mathrm{PhD}$ Thesis, Queensland University of Technology, Australia.

Hughes, H., Cooper, L., Flierl, M., Somerville, M., \& Chaudhary, N. (2018). The role of the university library in supporting international student transition: Insights from an Australian-American case study. The Journal of Academic Librarianship 44(5): 582-594

Hviid, P. \& Zittoun, T. (2008). Editorial introduction: Transitions in the process of education. European Journal of Psychology of Education, XXIII(2), 121-130.

Hyldegård, J. \& Hertzum, M. (2016), Coping with private and academic information needs abroad: An exploratory study of international students. Paper presented at the SIG-SI 
workshop at the ASIST Annual Meeting 2016.

Ivins, T., Copenhaver, K. \& Koclanes, A. (2017). Adult transitional theory and transfer shock in higher education: Practices from the literature. Reference Services Review, 45(2), 244257.

Johnston, J. (2016), Conversation-based programming and newcomer integration: A case study of the Språkhörnan program at Malmö City Library. Library \& Information Science Research, 38(1), 10-17.

Johnston, J. (2017). Friendship potential: Conversation-based programming and immigrant integration. Journal of Librarianship and Information Science.

Johnston, N. (2014). Understanding the information literacy experiences of EFL (English as a Foreign Language) students. PhD Thesis, Queensland University of Technology, Australia.

Kim, J. (2011). The birth of academic subalterns: How do foreign students embody the global hegemony of American universities? Journal of Studies in International Education, 16(5), 455-476.

Kralik, D, Visentin, K. \& van Loon A (2006) Transition: A literature review. Journal of Advanced Nursing, 55(3), 320-9.

Kutner, L. \& Armstrong, A. (2012). Rethinking information literacy in a globalized world. Communications in Information Literacy, 6(1), 24-33.

Lauerson, C. (2015). The library as platform for the integration of international students. The Library Lab. Retrieved from https://christianlauersen.net/2015/10/29/the-library-asplatform-for-integration-of-international-students/

Lillis, T. \& Scott, M. (2007). Defining academic literacies research: Issues of epistemology, ideology and strategy. Journal of Applied Linguistics, 4(1), 5-32.

Lloyd, A. (2005). Information literacy: Different contexts, different concepts, different truths? Journal of Librarianship and Information Science, 37(2), 82-88.

Lloyd, A. (2007). Learning to put out the red stuff: Becoming information literate through discursive practice. Library Quarterly, 77(2), 181-198.

Meleis, A., Sawyer, L., Messias, D., Im, E-O., \& Schumacher, K. (2000). Experiencing transitions: An emerging middle-range theory. Advanced Nursing Science, 23(1), 12-28.

MLA (Modern Language Association) (2013). Highlights of the MLA's 2013 survey of enrollments in languages other than English. Retrieved from http://www.mla.org/pdf/2013_enrollment_survey_hig.pdf

Montgomery, C. \& McDowell, L. (2009). Social networks and the international student experience: An international community of practice? Journal of Studies in International Education, 13(4), 455-466.

Morgan, P.K. (2015). Pausing at the threshold. portal: Libraries and the Academy, 15(1), 183195.

Peters, D. (2010). International students and academic libraries: A survey of issues and annotated bibliography. Lanham: Rowman \& Littlefield.

Powell, P. (2014). Retention and resistance: Writing instruction and students who leave. Logan: Utah State University Press.

Reyes, B., Hicks, A., \& Maxson, B. (2018). Information literacy practices of Spanish-speaking graduate students at the University of Kansas. portal: Libraries and the Academy, 18(3), 595-615.

Schatzki, T. (2002). The site of the social: A philosophical account of the constitution of social 
life and change. University Park: Pennsylvania State University Press.

Schatzki, T. (2012). A primer on practices. In: J. Higgs, R. Barnett, S. Billett, M. Hutchings \& F. Trede (Eds.), Practice-based education: Perspectives and strategies (pp.13-26). Rotterdam: Sense Publishers.

Schumacher, K. \& Meleis, A. (1994). Transitions: A central concept in nursing. Image: Journal of Nursing Scholarship 26(2), 119-27.

Volet, S. \& Jones, C. (2012). Cultural transitions in higher education: Individual adaptation, transformation and engagement. In: S. Karabenick \& T. Urdan (Eds), Transitions across schools and cultures (pp.241-284). Bingley: Emerald.

Wenger, E. (1998). Communities of practice: Learning, meaning, and identity. Cambridge: Cambridge University Press.

Wilkinson, L. (2014). The problem with threshold concepts. Sense and Reference. Available at https://senseandreference.wordpress.com/2014/06/19/the-problem-with-thresholdconcepts/

Zhao, J. C., \& Mawhinney, T. (2015). Comparison of native Chinese-speaking and native English-speaking engineering students' information literacy challenges. The Journal of Academic Librarianship, 41(6), 712-724. 